\title{
SURGICAL TREATMENT OF CARCINOMA OESOPHAGUS AT B P KOIRALA MEMORIAL CANCER HOSPITAL, BHARATPUR
}

\author{
Lamichhane N*, Tan Z B*, Neupane P R* \\ Thakur B K*, Shrestha B M*, Dhakal H P*
}

\section{ABSTRACT}

To review resectability, lymph node status and post-operative complications in cases of carcinoma of oesophagus treated surgically at B P Koirala memorial cancer hospital (BPKMCH), we reviewed the medical records of 16 surgically treated cases of carcinoma oesophagus from January 2001 to March 2002. There were 5 patients in stage II $_{\mathrm{a}}$ and 9 patients in stage III. Tumor was resectable in 14 out of 16 patients $(87.5 \%)$. There was no perioperative mortality. Anastomotic leak was seen in one case. Out of 14 resected specimens, $7(50 \%)$ of them had lymph node metastasis. Oesophagectomy is a safe procedure if done in a well-selected group of patients. Resectability is considerably high with minimal perioperative complications.

Key Words: Carcinoma oesophagus, surgical therapy, lymphnode metastasis.

\section{INTRODUCTION}

Oesophageal cancer represents the third most common gastrointestinal malignancy and ranks among the top ten cancers worldwide. ${ }^{1}$ The incidence of oesophageal cancer varies considerably relative to geographic location; high incidence areas have been identified within the Caspian littoral region of northern Iran, Southern republics of the former Soviet Union, and northern China where the incidence exceeds 100 in 100,000 individuals. ${ }^{2}$ The incidence of oesophageal cancer ranges from 10 to 50 in 100,000 in Sri Lanka, India, South Africa, France, and Switzerland. ${ }^{3}$ Squamous cell carcinoma of oesophagus is seen more frequently in the developing world. ${ }^{4}$ Here we present 16 surgically treated cases of carcinoma oesophagus at our institution within last 15 months.

\section{MATERIALS AND METHODS}

Cases of carcinoma oesophagus from January 2001 to March 2002 were reviewed from medical record section BPKMCH.

Criteria for operation were affirmed on the basis of transluminal extension of disease on CT scan of chest and /or by barium swallow. Total of sixteen cases were selected for surgical resection. Therefore other cases where investigations were not complete for some reason or directly referred to Radiation or Medical Oncologist were excluded from the study. All cases were histopathologically proven before procedure. Patients were admitted 4 to 7 days before surgery, kept on high protein liquid diet, or in intravenous caloric supplementation. Active chest physiotherapy was routinely given to all the patients

\footnotetext{
* B.P. Koirala Memorial Cancer Hospital, Bharatpur, Chitwan, Nepal.

Address for correspondence : $\quad$ Dr. Nirmal Lamichhane

Dept. of Surgical Oncology

B.P. Koirala Memorial Cancer Hospital, Bharatpur, Chitwan, Nepal.

Email: nlamichhane@doctor.com
} 
before surgery. For those with COPD, routine bronchodilators and antibiotics were prescribed preoperatively. Operations were carried out under general and epidural combined anesthesia. Average requirement of blood transfusion per patient was 2 to 3 units (1 unit $=350 \mathrm{ml}$ ).

Types of operations performed are listed in table 2. Lesions of different sites were resected in different way. For lesions at neck, transhiatal pull up of stomach was selected. For intrathoracic lesions above carina, right posterolateral thoracotomy, laparotomy, neck incision to make gastrooesophageal anastomosis (Mckeown operation) was chosen. For lesions below carina, left lateral thoracotomy with gastrooesophageal anastomosis above aortic arch or neck was done. Left posterolateral thoracotomy with gastrooesophageal anastomosis below the aortic arch or right posterolateral thoracotomy, laparotomy with intrathoracic gastrooesophageal anastomosis (Ivor lewis procedure) were performed for lesions at cardia. Resected margins of oesophagus were $5 \mathrm{~cm}$ or more from the lesion. Lymphadenectomy consisted of paraoesophageal nodes, subcarinal nodes, and paracardial nodes, nodes at lesser curvature of stomach and nodes at left gastric artery. In none of the cases, small or large bowel interpositions were performed. A feeding jejunostomy was done in 7 cases; naso-gastric feeding tube was placed in 6 cases for early feeding in the postoperative period.

Epidural analgesia was continued postoperatively with the hope of maximal relief of pain without sedation. Deep respiration and chest physiotherapy were started from the first postoperative day. Liquid diet was started as soon as the bowel sounds were evident, either from feeding jejunostomy or from naso-gastric feeding tube. On seventh of eighth postoperative days, oral sips were started, and then gradually shifted to normal diet.

\section{RESULTS}

Mean age of the patients was 59.93 years, with a range of 38 to 76 years. Male to female ratio was 1.12: 1.0. Cardinal symptoms of the disease were dysphagia to solid food, retrosternal discomfort and weight loss. Patient presented after discomfort for about 4.24 month in average, and mainly coming with the symptom of dysphagia. Eleven patients complained of dysphagia to even semisolid food. Average hemoglobin level was found to be $12.38 \pm 1.78 \mathrm{gm} / \mathrm{dl}$, serum total protein was $6.5 \pm 1.22 \mathrm{~g} / \mathrm{dl}(10$ being less than $6.8 \mathrm{gm} / \mathrm{dl})$ and serum albumin was $3.2 \pm 0.88 \mathrm{gm} / \mathrm{dl}$ (10 cases being less than 3.1 $\mathrm{gm} / \mathrm{dl}$.) in average. Clinocopathological characteristics of the patients are listed in table I.

Resection of oesophageal tumor was possible in 14 cases out of 16 cases (Resection rate 87.5\%). According to 1997 UICC TNM staging, there were 5 stage II $_{\mathrm{a}}$ cases and 9 stage III cases. Five were $\mathrm{T}_{3} \mathrm{~N}_{0} \mathrm{M}_{0}$ lesions, seven were $\mathrm{T}_{3} \mathrm{~N}_{1} \mathrm{M}_{0}$ and two were $\mathrm{T}_{4} \mathrm{~N}_{0} \mathrm{M}_{0}$. Seven out of 14 resected specimens had lymph node metastasis (lymph node metastasis rate 50\%). Total of 221 nodes was resected, average being 15.78 per patient (range 326). Thirty-three lymph nodes out of 221 total resected nodes showed cancer cells within them; degree of lymph node involvement was $14.93 \%$. Average hospital stay was 17 days.

Resected margins were positive in 2 cases, first case was transhiatal excision of distal neck lesion, and the other one was 